\title{
Effect of Passive Ultrasonic Irrigation over Organic Tissue of Simulated Internal Root Resorption
}

\author{
Amjad Abu Hasna $\mathbb{D}^{\mathrm{D}},{ }^{1}$ Jaiane Bandoli Monteiro $\mathbb{D}^{2},{ }^{2}$ Ricardo Toledo Abreu $\mathbb{D}^{1}$, \\ Wanessa Camillo, ${ }^{3}$ Amanda Guedes Nogueira Matuda $\mathbb{D}^{3},{ }^{3}$ Luciane Dias de Oliveira $\mathbb{D},{ }^{4}$ \\ Cesar Rogério Pucci $\mathbb{D}^{3},{ }^{3}$ and Cláudio Antonio Talge Carvalho $\mathbb{D}^{1}$ \\ ${ }^{1}$ Department of Restorative Dentistry, Endodontics Division, Institute of Science and Technology, \\ São Paulo State University (ICT-Unesp), São José Dos Campos, Brazil \\ ${ }^{2}$ Department of Dental Materials and Prosthodontics, Institute of Science and Technology, \\ São Paulo State University (ICT-Unesp), São José Dos Campos, Brazil \\ ${ }^{3}$ Department of Restorative Dentistry, Institute of Science and Technology, São Paulo State University (ICT-Unesp), \\ São José Dos Campos, Brazil \\ ${ }^{4}$ Department of Biosciences and Oral Diagnosis, Institute of Science and Technology, São Paulo State University (ICT-Unesp), \\ São José Dos Campos, Brazil \\ Correspondence should be addressed to Cesar Rogério Pucci; cesar@fosjc.unesp.br
}

Received 7 June 2021; Revised 13 September 2021; Accepted 15 October 2021; Published 29 October 2021

Academic Editor: Renato Casarin

Copyright (c) 2021 Amjad Abu Hasna et al. This is an open access article distributed under the Creative Commons Attribution License, which permits unrestricted use, distribution, and reproduction in any medium, provided the original work is properly cited.

\begin{abstract}
This study aimed to evaluate the efficacy of passive ultrasonic irrigation (PUI) on dissolving the organic tissue inside simulated internal root resorption (IRR) using sodium hypochlorite $(\mathrm{NaOCl})$ or chlorhexidine (CHX). A total of 40 human lower premolars were collected based on dimensional and morphological similarities. The roots were embedded in cylinders $(3 \mathrm{~cm}$ diameter; $2.5 \mathrm{~cm}$ height) of self-cured acrylic resin, and then an IRR was simulated. The specimens were divided into 4 groups $(n=10)$ according to irrigation protocols: group 1: $\mathrm{CHX}+\mathrm{PUI}$; group 2: $\mathrm{CHX}$; group 3: $\mathrm{NaOCl}+\mathrm{PUI}$; group 4: $\mathrm{NaOCl}$. The total irrigation time was $150 \mathrm{~s}$ at a flow rate of $5 \mathrm{~mL} / \mathrm{min}$. A tissue mass of porcine palatine mucosa was used to simulate the organic tissue, it was weighed before and after the irrigation using an analytic balance, and the difference between both readings was calculated and transferred to percentage values. Data were submitted to statistical analysis using two-way ANOVA (factors: irrigant type and with/without PUI) and Tukey's test for multiple comparisons among the experimental groups $(\alpha=0.05)$. There was a significant difference in both factors (irrigant: $p=0.04$; PUI: $p \leq 0.001$ ). The groups that used PUI were more effective in dissolving the organic tissue of the IRR simulation than the groups without PUI. PUI is more effective than the syringe and needle irrigation in organic tissue dissolution.
\end{abstract}

\section{Introduction}

The root resorption is a hard tissue loss activated by odontoclasts [1] because of a mechanical injury such as trauma, surgical procedures, and excessive pressure of an impacted tooth or a chemical irritation by hydrogen peroxide or other irritating agents [2]. It may be internal root resorption (IRR) resulted from infected or inflamed pulp tissue or external root resorption (ERR) resulted from periodontal infection [3] where the clastic precursor cells are predominantly recruited through the blood vessels.

The control of the IRR process depends fundamentally on cutting blood supply to the resorbing tissues through root canal treatment (RCT) which remains the only choice of management for such conditions when teeth are considered restorable and have a favorable prognosis [4].

Sodium hypochlorite $(\mathrm{NaOCl})$ is capable of dissolving the organic material during RCT [5], and it has a wide 
antimicrobial action, detoxifies endotoxins, and reduces matrix metalloproteinase (MMP) production [6-8]. However, weak evidence is found in the literature about chlorhexidine (CHX) dissolving capacity [9]; still, it has a wide antimicrobial action [10]. Otherwise, both can reach untouched areas that the mechanical instrumentation cannot [11]. This may be related to many factors including the endodontic instrument taper, mechanical properties $[12,13]$, and the preliminary diagnosis [14-16].

Syringes and needles, gutta percha points, EndoActivator, sonic activation, EndoVac, and others were reported as effective devices to improve the irrigation [17]. Beside passive ultrasonic irrigation (PUI) which is a widely used technique [18], it improves mechanical $\mathrm{NaOCl}$ penetration [19], making it more effective over microorganisms [6] and organic tissues [20,21]. Conversely, other studies show no further advantage of PUI activation over other techniques $[22,23]$.

This study aimed to evaluate the mechanical effect of PUI in dissolving organic tissue using $2.5 \% \mathrm{NaOCl}$ and $2 \% \mathrm{CHX}$ gel as endodontic irrigants. The null hypothesis tested was that the PUI activation would not improve the dissolving capacity of these irrigants.

\section{Materials and Methods}

This in vitro study was approved by the research ethics committee of São Paulo State University, Institute of Science and Technology ( $n$ 2.494.487). A total of 40 human lower premolars indicated for surgical extraction were obtained from patients undergoing orthodontic or periodontal treatment. Teeth were collected based on dimensional and morphological similarities which were evaluated by periapical radiography of all included teeth. Criteria such as the pulp chamber and root canal size, the presence of calcification, the presence of extra canals, endodontically treated teeth, and pulp calcifications were all evaluated while selecting the teeth to be included in this in vitro study.

2.1. Specimen Preparation. The crown of each tooth was cross-sectioned at the cementoenamel junction using a carborundum disk (Dentorium, New York, USA) under cooling, and the root length was standardized at $16 \pm 0.5 \mathrm{~mm}$. All roots were instrumented with K-file \#15 (Dentsply Ind. Com. Ltda, Petrópolis, RJ, Brazil) and irrigated with $3 \mathrm{~mL}$ of $1 \% \mathrm{NaOCl}$. The roots were embedded in cylinders ( $3 \mathrm{~cm}$ diameter; $2.5 \mathrm{~cm}$ height) of self-cured acrylic resin (TDV, Santa Catarina, Brazil), and then an IRR was simulated [24] as shown in Figure 1 and detailed below.

With the aid of a dental parallelometer (Bio-Art, São Paulo, Brazil), the roots were fixed in cylinders $(3 \mathrm{~cm}$ of diameter and $2.5 \mathrm{~cm}$ of height) of autopolymerized acrylic resin $\left(\mathrm{TDV}^{\circledast}\right.$, Santa Catarina State, Brazil) molded in silicone models (Silibor, Classico Artigos Odontológicos Ltda., São Paulo). In each resin block, 3 holes were made by using an electric drill with a bur of $3.96 \mathrm{~mm}$ of diameter, approximately $3 \mathrm{~mm}$ away from the root position and parallel to the long axis of the root, forming a triangle.
Using the IsoMet 1000 precision cutting machine (Buehler, Illinois, USA), the block was cross-sectioned at $8 \mathrm{~mm}$ far from its upper surface and perpendicularly to its long axis. Two portions, one upper and one lower, were obtained. Three cylindrical screws, $3.5 \mathrm{~mm}$ in diameter, were positioned in the holes and fixed with the aid of nuts to retake the original position of the block when necessary.

To simulate an internal resorption, a cavity of $1.25 \mathrm{~mm}$ of depth and $2.5 \mathrm{~mm}$ of diameter was prepared with diamond round bur 3030 (KG Sorensen, São Paulo, Brazil) on the inferior surface of the upper portion of the tooth sample and on the superior surface of the lower portion of the tooth sample (Figure 1). The upper and lower portions of the samples were repositioned with the screws.

2.2. The Organic Material. A tissue mass of porcine palatine mucosa was used to simulate the organic tissue [25] and adapted within the IRR simulation. It was weighed before the irrigation using an analytic balance (ATX UniBloc, Shimadzu, SP, Brazil); once the irrigation protocol was performed for each group $(n=10)$, the material was removed and dried using absorbing paper for 4 minutes in order to avoid humidity to affect the balancing process and finally weighed again; however, the mass remained partially wet.

2.3. The Experimental Groups. The total irrigation time was $150 \mathrm{~s}$ at a flow rate of $5 \mathrm{~mL} / \mathrm{min}$ as the following:

(i) Group 1: CHX + PUI: the canals were filled with $1 \mathrm{~mL}$ of $2 \%$ CHX gel and irrigated with $5 \mathrm{~mL}$ of saline solution by typical syringe irrigation without PUI and then filled with $1 \mathrm{~mL}$ of $2 \%$ CHX gel and irrigated with $5 \mathrm{~mL}$ of saline solution activated with PUI. Finally, the canals were washed continually by $2.5 \mathrm{~mL}$ of ethylenediaminetetraacetic acid (EDTA) $17 \%$ for 30 seconds.

(ii) Group 2: CHX: the canals were filled with $2 \mathrm{~mL}$ of $2 \%$ CHX gel and irrigated with $10 \mathrm{~mL}$ of saline solution by typical syringe irrigation without PUI activation and washed finally by $2.5 \mathrm{~mL}$ of ethylenediaminetetraacetic acid (EDTA) $17 \%$ for 30 seconds.

(iii) Group 3: $\mathrm{NaOCl}+\mathrm{PUI}$ : the canals were irrigated with $5 \mathrm{~mL}$ of $2.5 \% \mathrm{NaOCl}$ by typical syringe irrigation using the needle 30G (NaviTip, Ultradent, South Jordan, UT, USA) without PUI and then $5 \mathrm{~mL}$ activated with PUI. Finally, the canals were washed continually by $2.5 \mathrm{~mL}$ of ethylenediaminetetraacetic acid (EDTA) $17 \%$ for 30 seconds.

(iv) Group 4: NaOCl: the canals were irrigated with $10 \mathrm{~mL}$ of $2.5 \% \mathrm{NaOCl}$ by typical syringe irrigation utilizing irrigation needle $30 \mathrm{G}$ without PUI activation and finally washed by $2.5 \mathrm{~mL}$ of ethylenediaminetetraacetic acid (EDTA) $17 \%$ for 30 seconds. 


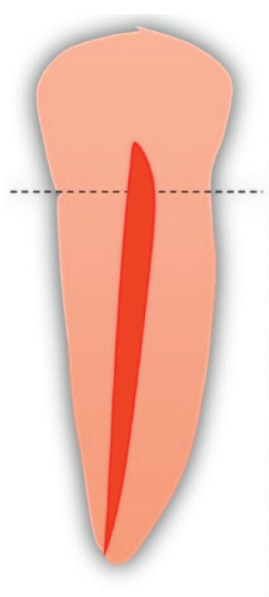

(a)

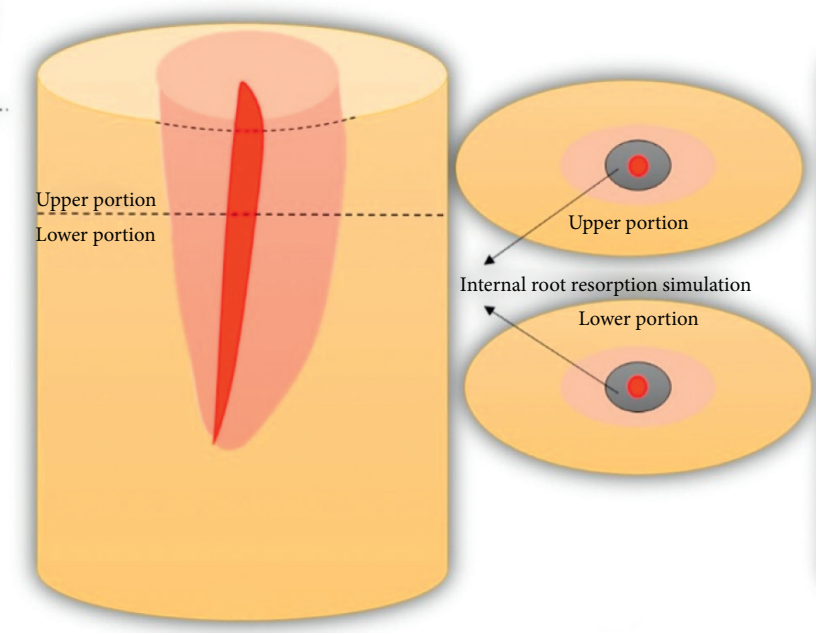

(b) (c)

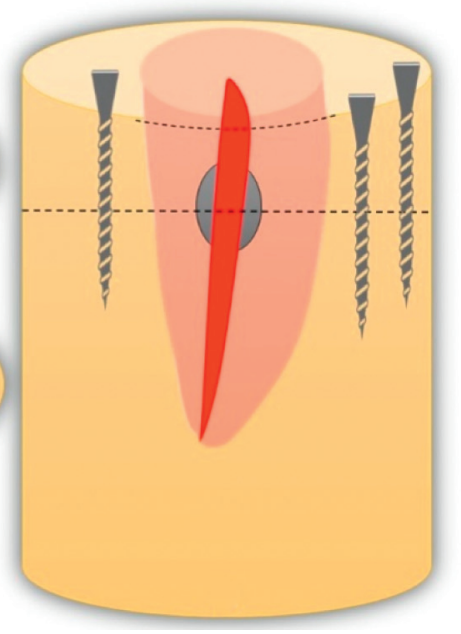

(d)

FIgURE 1: Schematic illustration of the IRR simulation. (a) The crown of each tooth was cross-sectioned at the cementoenamel junction, and (b) the roots were embedded in cylinders $(3 \mathrm{~cm}$ diameter; $2.5 \mathrm{~cm}$ height) of self-cured acrylic resin. Then, (c) IRR was simulated, and (d) finally, the specimens were ready.

2.4. Passive Ultrasonic Irrigation. PUI activation was performed using an E1-Irrisonic stainless-steel tip (Helse, Santa Rosa de Viterbo, Brazil) at the working length using Soni ${ }^{\circledR}$ II (Ortus, Paraná, Brazil) at 10\% frequency. No movement was performed during PUI activation to avoid any contact between the ultrasonic tip and the canal walls.

2.5. Statistical Analysis. The difference between both readings (before and after irrigation) was calculated and transferred to percentage values. The obtained data were submitted to statistical analysis using two-way ANOVA (factors: irrigant type and activation methods: with/without PUI) and Tukey test for multiple comparisons among the experimental groups $(\alpha=0.05)$.

\section{Results}

Tables 1 and 2 present the results of Tukey's test for the factors irrigant and PUI, respectively. There was a significant difference in both factors (irrigant: $p=0.04$; PUI: $p \leq 0.001$ ). The groups that used PUI were more effective in dissolving the organic tissue of the IRR simulation than the groups without PUI as seen in Figure 2.

\section{Discussion}

The present study evaluated the effectivity of PUI in dissolving organic tissue when $\mathrm{NaOCl}$ and $\mathrm{CHX}$ were used. It can be noted that the mechanical effect of PUI was more evident than the chemical effect of irrigants over organic tissue dissolving (Table 2). The results showed that the groups of PUI activation were more effective over organic material than the groups that used conventional needle and syringe irrigation, and therefore, the null hypothesis was rejected.
TABLE 1: Tukey's test $(\alpha=0.05)$ comparison of readings (means (\%) and standard deviation $( \pm \mathrm{SD})$ ) for the isolated factor irrigant.

\begin{tabular}{lc}
\hline Type of irrigant & Means $( \pm$ SD $)$ \\
\hline $\mathrm{NaOCl}$ & $43.89( \pm 17.65)^{\mathrm{a}}$ \\
$\mathrm{CHX}$ & $34.26( \pm 17.1)^{\mathrm{b}}$ \\
\hline
\end{tabular}

Mean values with different letters show a significant difference.

TABLE 2: Tukey's test $(\alpha=0.05)$ comparison of readings (means (\%) and standard deviation $( \pm \mathrm{SD})$ ) for the isolated factor PUI.

\begin{tabular}{lc}
\hline PUI & Means $( \pm$ SD) \\
\hline Without & $29.21( \pm 14.33)^{\mathrm{A}}$ \\
With & $48.95( \pm 15.56)^{\mathrm{B}}$
\end{tabular}

Mean values with different letters show a significant difference.

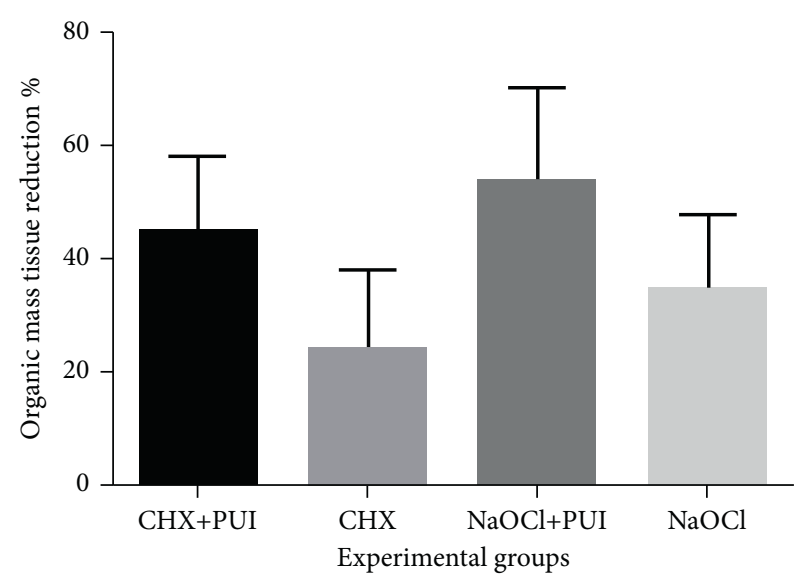

FIgURE 2: The statistical difference among the four experimental groups. 
International Journal of Dentistry

Ultrasonic irrigation (UI) was introduced firstly by Richman to improve irrigants' action [26] in debris removal and organic tissue dissolution [27]. However, it is less effective than PUI due to reduced acoustic streaming [28]. Conversely, PUI has greater acoustic streaming and lower risk to cause iatrogenic accidents because it uses noncutting and smooth inserts [28-30].

In previous studies, PUI was effective in improving organic tissue dissolving due to the effect of the acoustic streaming and showed to be more effective than conventional needle and syringe irrigation [31]. Similar results were found in this study as PUI was more effective than conventional needle and syringe irrigation. The study of AlJadaa et al. [23] proved that the acoustic stream of PUI is more effective than the sonic stream in dissolving organic material, and this may be explained by its capacity to increase the irrigant temperature [32] or because it reduces the irrigant superficial tension playing the role of a chemical surfactant [25]. The results of the present study showed that PUI improves the organic tissue dissolution.

More recently, it was found that PUI is effective in reducing the organic material of narrow, infected, and curved root canals without the need for greater taper instruments; however, without the use of PUI, $\geq 35$ taper instruments are indicated [33]. This factor was not evaluated in this in vitro study; however, it may be evaluated in future studies as minimally invasive endodontics is gaining a greater space.

$\mathrm{NaOCl}$ is an effective irrigant in dissolving organic material [34], and this agrees with other studies which showed similar results in bovine teeth but with $2.5 \%$ concentration $[35,36]$. Similar results were found in the present study as $2.5 \% \mathrm{NaOCl}$ was effective in organic tissue dissolution. However, the presence of EDTA as a final washing solution may reduce the dissolution capacity of $\mathrm{NaOCl}$ according to recent studies [37, 38].

$\mathrm{CHX}$, as well, was studied to evaluate its dissolving capacity of organic tissues at a concentration of $2 \%$ [9]. In this study, the group CHX (without PUI) presented the lowest results with organic tissue dissolution (Figure 2 and Table 1) when compared with other groups, which is in agreement with other studies [39, 40]. Despite CHX presents long-lasting antimicrobial activity, as an endodontic irrigant, the lack of tissue dissolving capacity of $\mathrm{CHX}$ is a considerable drawback [41, 42].

Finally, it is important to mention that this in vitro study has some limitations as the balance process has an error margin because of humidity. Regardless the irrigant type, PUI was able to improve the dissolving capacity of the irrigant, and this is because of the acoustic streaming that maximizes the irrigant dissolving capacity over organic tissue. PUI was more effective than conventional needle and syringe irrigation, which agrees with other studies revealing the reduced effectivity of this method and the advantage of PUI over this method [31].

\section{Conclusion}

Passive ultrasonic irrigation is more effective than the conventional needle and syringe irrigation in organic tissue dissolution.

\section{Data Availability}

The data used to support the findings of this study are available at https://doi.org/10.7910/DVN/FFJD8A.

\section{Conflicts of Interest}

The authors declare no conflicts of interest.

\section{Acknowledgments}

The authors wish to thank São Paulo State University for all their unconditional support in writing this paper.

\section{References}

[1] S. Patel and T. P. Ford, "Is the resorption external or internal?" Dental Update, vol. 34, no. 4, pp. 222-224, 2007.

[2] S. Friedman, I. Rotstein, H. Libfeld, A. Stabholz, and I. Heling, "Incidence of external root resorption and esthetic results in 58 bleached pulpless teeth," Dental Traumatology, vol. 4, no. 1, pp. 23-26, 1988.

[3] Z. Fuss, I. Tsesis, and S. Lin, "Root resorption-diagnosis, classification and treatment choices based on stimulation factors," Dental Traumatology, vol. 19, no. 4, pp. 175-182, 2003.

[4] S. Patel, D. Ricucci, C. Durak, and F. Tay, "Internal root resorption: a review," Journal of Endodontics, vol. 36, no. 7, pp. 1107-1121, 2010.

[5] N. Naenni, K. Thoma, and M. Zehnder, "Soft tissue dissolution capacity of currently used and potential endodontic irrigants," Journal of Endodontics, vol. 30, no. 11, pp. 785-787, 2004.

[6] A. Abu Hasna, L. Pereira Da Silva, F. C. Pelegrini, C. L. R. Ferreira, L. D. de Oliveira, and C. A. T. Carvalho, "Effect of sodium hypochlorite solution and gel with/without passive ultrasonic irrigation on Enterococcus faecalis, Escherichia coli and their endotoxins," F1000Research, vol. 9, p. 642, 2020.

[7] A. S. Carvalho, L. D. d. Oliveira, F. G. d. R. Cardoso, F. E. d. Oliveira, M. C. Valera, and C. A. T. Carvalho, "Limewater and polymyxin $\mathrm{B}$ associated with $\mathrm{NaOCl}$ for endotoxin detoxification in root canal with necrotic pulp," Brazilian Dental Journal, vol. 27, no. 5, pp. 573-577, 2016.

[8] C. A. T. Carvalho, A. A. Hasna, A. S. Carvalho et al., "Clinical study of sodium hypochlorite, polymyxin B and limewater effect on MMP-3,-8,-9 in apical periodontitis," Brazilian Dental Journal, vol. 31, no. 2, pp. 116-121, 2020.

[9] B. P. F. A. Gomes, M. E. Vianna, A. A. Zaia, J. F. A. Almeida, F. J. Souza-Filho, and C. C. R. Ferraz, "Chlorhexidine in endodontics," Brazilian Dental Journal, vol. 24, no. 2, pp. 89-102, 2013.

[10] N. S. Ferreira, F. C. Martinho, F. G. R. Cardoso, G. G. Nascimento, C. A. T. Carvalho, and M. C. Valera, "Microbiological profile resistant to different intracanal medications in primary endodontic infections," Journal of Endodontics, vol. 41, no. 6, pp. 824-830, 2015.

[11] M.-K. Wu, L. W. M. van der Sluis, and P. R. Wesselink, "The capability of two hand instrumentation techniques to remove the inner layer of dentine in oval canals," International Endodontic Journal, vol. 36, no. 3, pp. 218-224, 2003.

[12] A. Zanza, M. Seracchiani, D. Di Nardo, R. Reda, G. Gambarini, and L. Testarelli, "A paradigm shift for torsional stiffness of nickel-titanium rotary instruments: a finite 
element analysis," Journal of Endodontics, vol. 47, no. 7, pp. 1149-1156, 2021.

[13] C. H. Ribeiro Camargo, "Cyclic fatigue, torsional failure, and flexural resistance of rotary and reciprocating instruments," Journal of Conservative Dentistry, vol. 23, no. 4, pp. 364-369, 2020.

[14] R. Reda, A. Zanza, A. Mazzoni, A. Cicconetti, L. Testarelli, and D. Di Nardo, "An update of the possible applications of magnetic resonance imaging (MRI) in dentistry: a literature review," Journal of Imaging, vol. 7, p. 5, 2021.

[15] C. H. Ferrari, A. Abu Hasna, and F. C. Martinho, "Three Dimensional mapping of the root apex: distances between apexes and anatomical structures and external cortical plates," Brazilian Oral Research, vol. 35, p. e022, 2021.

[16] A. A. Hasna, A. B. A. Pinto, G. Minhoto, and B. J. M. Corazza, "Pictograph system for diagnosis making and data management in endodontics," Brazilian Dental Science, vol. 23, pp. 1-6, 2020.

[17] M. Haapasalo, Y. Shen, W. Qian, and Y. Gao, "Irrigation in endodontics," Dental Clinics of North America, vol. 54, no. 2, pp. 291-312, 2010.

[18] F. C. Martinho, C. A. T. Carvalho, L. D. Oliveira et al., "Comparison of different dentin pretreatment protocols on the bond strength of glass fiber post using self-etching adhesive," Journal of Endodontics, vol. 41, no. 1, pp. 83-87, 2015.

[19] M. Sáinz-Pardo, R. Estevez, Ó. V. d. Pablo, G. Rossi-Fedele, and R. Cisneros, "Root canal penetration of a sodium hypochlorite mixture using sonic or ultrasonic activation," Brazilian Dental Journal, vol. 25, no. 6, pp. 489-493, 2014.

[20] H. Martin, "Ultrasonic disinfection of the root canal," Oral Surgery, Oral Medicine, Oral Pathology, vol. 42, no. 1, pp. 92-99, 1976.

[21] L. W. M. van der Sluis, M. Versluis, M. K. Wu, and P. R. Wesselink, "Passive ultrasonic irrigation of the root canal: a review of the literature," International Endodontic Journal, vol. 40, no. 6, pp. 415-426, 2007.

[22] A. J. Conde, R. Estevez, G. Loroño, Ó. Valencia de Pablo, G. Rossi-Fedele, and R. Cisneros, "Effect of sonic and ultrasonic activation on organic tissue dissolution from simulated grooves in root canals using sodium hypochlorite and EDTA," International Endodontic Journal, vol. 50, no. 10, pp. 976-982, 2017.

[23] A. Al-Jadaa, F. Paqué, T. Attin, and M. Zehnder, "Acoustic hypochlorite activation in simulated curved canals," Journal of Endodontics, vol. 35, no. 10, pp. 1408-1411, 2009.

[24] R. Abreu, J. Monteiro, A. Abu-Hasna et al., "Bond strength of cemented fiber posts to teeth with simulated internal root resorption," Journal of Clinical and Experimental Dentistry, vol. 12, no. 3, pp. e277-e284, 2020.

[25] R. Estevez, A. J. Conde, O. Valencia de Pablo, F. de la Torre, G. Rossi-Fedele, and R. Cisneros, "Effect of passive ultrasonic activation on organic tissue dissolution from simulated grooves in root canals using sodium hypochlorite with or without surfactants and EDTA," Journal of Endodontics, vol. 43, no. 7, pp. 1161-1165, 2017.

[26] M. J. Richman, "The use of ultrasonics in root canal therapy and root resection," Journal of Dental Medicine, vol. 12, pp. 12-18, 1957.

[27] A. D. Walmsley, "Ultrasound and root canal treatment: the need for scientific evaluation," International Endodontic Journal, vol. 20, no. 3, pp. 105-111, 1987.

[28] M. Ahmad, T. R. Pitt Ford, and L. A. Crum, "Ultrasonic debridement of root canals: acoustic streaming and its possible role," Journal of Endodontics, vol. 13, no. 10, pp. 490-499, 1987.

[29] M. Ahmad, T. R. Pitt Ford, L. A. Crum, and A. J. Walton, "Ultrasonic debridement of root canals: acoustic cavitation and its relevance," Journal of Endodontics, vol. 14, no. 10, pp. 486-493, 1988.

[30] M. Ahmad, R. A. Roy, and A. G. Kamarudin, "Observations of acoustic streaming fields around an oscillating ultrasonic file," Dental Traumatology, vol. 8, no. 5, pp. 189-194, 1992.

[31] L. W. M. van der Sluis, M. K. Wu, and P. R. Wesselink, “The evaluation of removal of calcium hydroxide paste from an artificial standardized groove in the apical root canal using different irrigation methodologies," International Endodontic Journal, vol. 40, no. 1, pp. 52-57, 2007.

[32] A. Al-Jadaa, F. Paqué, T. Attin, and M. Zehnder, "Necrotic pulp tissue dissolution by passive ultrasonic irrigation in simulated accessory canals: impact of canal location and angulation," International Endodontic Journal, vol. 42, no. 1, pp. 59-65, 2009.

[33] M. Alcota, J. Osorio, C. Díaz et al., "Effect of the passive ultrasonic irrigation and the apical diameter size on the debridement efficacy of infected root canals: a multivariate statistical assessment of histological data," Applied Sciences, vol. 11, no. 16, p. 7495, 2021.

[34] F. K. Cobankara, H. B. Ozkan, and A. Terlemez, "Comparison of organic tissue dissolution capacities of sodium hypochlorite and chlorine dioxide," Journal of Endodontics, vol. 36, no. 2, pp. 272-274, 2010.

[35] D. Arslan, M. B Guneser, A Kustarci, K Er, and S. H Siso, "Pulp tissue dissolution capacity of QMix 2in1 irrigation solution," European Journal of Dermatology, vol. 9, no. 3, pp. 423-427, 2015.

[36] R. S. Niewierowski, L. R. Scalzilli, R. D. Morgental et al., "Bovine pulp tissue dissolution ability of irrigants associated or not to ultrasonic agitation," Brazilian Dental Journal, vol. 26, no. 5, pp. 537-540, 2015.

[37] L. H. S. de Almeida, N. G. e. S. Leonardo, A. P. N. Gomes, E. M. Souza, and F. G. Pappen, "Influence of EDTA and dentine in tissue dissolution ability of sodium hypochlorite," Australian Endodontic Journal, vol. 41, no. 1, pp. 7-11, 2015.

[38] Ö. İ. Ulusoy, İ. G. Savur, T. Alaçam, and B. Çelik, "The effectiveness of various irrigation protocols on organic tissue removal from simulated internal resorption defects," International Endodontic Journal, vol. 51, no. 9, pp. 1030-1036, 2018.

[39] J. Marley, D. Ferguson, and G. Hartwell, "Effects of chlorhexidine gluconate as an endodontic irrigant on the apical seal: short-term results," Journal of Endodontics, vol. 27, no. 12 , pp. $775-778,2001$.

[40] L. A. Okino, E. L. Siqueira, M. Santos, A. C. Bombana, and J. A. P. Figueiredo, "Dissolution of pulp tissue by aqueous solution of chlorhexidine digluconate and chlorhexidine digluconate gel," International Endodontic Journal, vol. 37, no. 1, pp. 38-41, 2004.

[41] A. E. Del Carpio-Perochena, C. M. Bramante, M. A. H. Duarte et al., "Biofilm dissolution and cleaning ability of different irrigant solutions on intraorally infected dentin," Journal of Endodontics, vol. 37, no. 8, pp. 1134-1138, 2011.

[42] A. Khademi, E. Usefian, and M. Feizianfard, "Tissue dissolving ability of several endodontic irrigants on bovine pulp tissue," Iranian Endodontic Journal, vol. 2, no. 2, pp. 65-68, 2007. 